\title{
Collective Text Editor: A New Interface Focused on Interaction Design
}

\author{
Patricia Alejandra Behar, Alexandra Lorandi Macedo, Jaire Ederson Passos, \\ and Paula Caroline Schifino Jardim Passos
}

\author{
NUTED - Núcleo de Tecnologia Digital aplicada à Educação, Universidade Federal do Rio \\ Grande do Sul, Av. Paulo Gama, 110 - Prédio 12105 - 4 andar sala 401 - 90040-060 - Porto \\ Alegre (RS), Brazil \\ pbehar@terra.com.br, \\ \{alorandimacedo, jairepassos, paulacarolinejardim\}@gmail.com
}

\begin{abstract}
The Collective Text Editor ETC is a tool that follows Web 2.0 philosophy. Thus, its aim is to foster collaborative work mediated by computer and to create a space where the synchronous and asynchronous construction of collective texts among geographically dispersed users can be encouraged. The ETC is linked to a research project of NUTED/UFRGS. The present article deals with the reconstruction of the interface so as to adapt it to the current technological demands, giving it credibility and new personality.
\end{abstract}

Keywords: Collective text editor, Interface for collective learning.

\section{Scenario}

The Collective Text Editor - ETC ${ }^{1}$ - aims to provide a space for collective elaboration of texts, synchronously or asynchronously, by users dispersed geographically. This tool was developed by NUTED $^{2}$ (Nucleus of Digital Technology applied to Education) of the Federal University of Rio Grande do Sul. The first version of ETC was built in 2001. Since then, the editor has been used in different teaching-learning situations, considering a variety of work groups, among teachers and students from graduate, extension and post graduate courses in different areas of knowledge.

Throughout the use, NUTED has always prioritized the improvement of the tool following evaluations made by users. Several actions, in this sense [2], [3] and [4] have been developed and implemented in order to enhance the editor and to contemplate the demands presented. The research group team is currently readapting the ETC's visual interface and navigation, aiming to update and innovate.

Within the new key-concepts originating from Web 2.0 cooperation and interaction can be highlighted. To promote this process, however, it is necessary that the interface follow the principles of usability, contemplating users and their objectives. In the case of ETC, visual communication criteria were included and discussed since its initial

\footnotetext{
${ }^{1}$ Available in: www.nuted.edu.ufrgs.br/etc

${ }^{2}$ www.nuted.edu.ufrgs.br
} 
implementation. But, with technological advances, it is necessary to review this application so as to approximate the editor to new visual constructions that emerge from Web 2.0 technologies.

The present article presents a new graphic project which aims to provide greater comfort and visual harmony. It is a more attractive and intuitive interface whose graphic design has been improved offering a better environment where interaction and cooperation can be developed. It is believed that, this way, better results in the interactive processes can be reached as a result of the collective constructions in the editor. Thus, this article presents the pedagogical foundations that have underlain the development of ETC, it describes the design principles highlighting not only the main problems found in the previous version but also the solutions that have been proposed for the new, ending with final considerations.

\section{Educational Support for ETC}

The ETC, as its name suggests, is a Collective Text Editor. In this sense, it is necessary to define what the present article understands by such concept. The term "collective" depends on the kind of interaction that takes place. In this case, this study deals with the inter-individual relations occurring among participants in an activity, in other words, the collective elaboration of a text supported by Piaget's premises [12]. It is important to emphasize that the theoretical support of the present study is based upon Jean Piaget [12], according to the definitions of interaction types taking place among subjects (individual or inter-individual).

The collective construction of a text implies a dynamic interaction among people involved. It is understood that an interaction occurs between subject and object. This is a dialectical movement and is part of a process of knowledge construction. We highlight that subject and object relating to one another are an undissociated whole and, in this context, the object can be considered the support material, the tools of the environment, the content discussed and constructed besides the subjects involved.

In a process of collective authorship there are moments in which subjects coordinate different viewpoints. Thus, this is understood as a movement of displacement of perspectives, of opening to new meanings, new relations and connections between writing objects, between events and characters, building new and permanent authorship possibilities [1]. In this social relation the subject is "we" and object is the other subjects. Thus, "(...) social facts are exactly parallel to mental facts, with an only difference that "we" is always referred to as "I" and cooperation, by simple operations" [12]. To coordinate different perspectives about the same theme, the subject needs to decentralize, in other words, to analyze different viewpoints through a view that is not his/her own.

Aiming to support this movement of interaction, the ETC makes functionalities available that favor synchronous and asynchronous communication. We understand that the collective text editor offers conditions for a dynamic self-organization of the group so that the common goal is a coherent and meaningful whole. Therefore, collective construction implicates eminently in the actions of subjects. Such actions refer to physical and cognitive coordination that can change each subject in particular as well as one in relation to the other [13]. This collective movement forms a 
contribution network and exhibits a relevant construction process in that it centralizes ideas and reveals propositions based on different life experiences.

Educational professionals have realized the potential of Web 2.0 in learning processes. Among its advantages we can highlight the power of interaction tools to foster group consciousness, keeping participants permanently informed about each others' work as well as about production as a whole [18]. Besides, technology that supports collective edition can be not only attractive but also convenient to the teacher who is able to identify each student's process in relation to the group, having as a resource for such the tools for production follow up available in the ETC.

It is clear that the relevance to the continuity and improvement of ETC lies in the search to develop tools that respond to the priorities of educational needs. That is why applications and analyses are permanently supported by the public who show the potential of use and projections of the tool. Thus, based on these principles, a new interface development was articulated aiming to support the dynamic exchanges generated from the collective construction.

\section{Design Addressed to User}

Interaction design is an area of design devoted to projecting systems that enable communication and work through computer interfaces. Many products that require human interaction are not developed with the users in mind but are focused on the functions that such products should perform. Re-directing this focus, interaction design brings usability into the design process. Preece [14] defines this activity as "the design of interactive products that provide support to people's daily activities" (p.28). This way, it is centered on the user, aiming to provide comfort for his/her activities and efficacy in the results.

The main focus of interaction design is to offer the user favorable conditions so that objectives are reached and so that the development of the activities can occur nicely. To do so, usability goals are established in order to highlight the main points to be observed in the development of a system. Within these usability goals we list system efficacy concerning how successful the task performance can be; efficiency that is related to the way the system helps the user perform his/her tasks and if it is productive. Moreover, security issues, which concern users not being exposed to undesirable situations, preventing errors and enabling retrievals; and utility, which evaluates whether the system provides enough and adequate functions to help users in activities he/she needs to perform [14].

Usability means optimizing the relations among people and interactive products. In the case of ETC, the interaction design aims, above all, to promote textual production through group work. This project needs, therefore, to highlight usability goals so as to minimize the cognitive $\operatorname{load}^{3}$, so the user can concentrate his efforts in the activity under way and not in learning to use the system. Fleming [9] claims that time spent trying to figure out how a site works hinders the comprehension of the content. It is necessary that the interface be easy to learn, intuitive, with easy navigation and easy to remember in a first contact, guaranteeing users a good performance next time they need to use the system.

${ }^{3}$ Cognitive load refers to the demands made upon the learner's work memory during instruction. 
For the new ETC project, two points were then highlighted: the capacity to learn (learnability) and the capacity to memorize (memorability). The capacity to learn concerns how long it takes to initiate the system and to learn to perform a wider range of activities. The capacity to memorize, in its turn, is related to the kind of support that is provided the user to help him/her remember how to use something, especially those things that are not used very frequently [14].

Besides the usability goals, there are also those related to the experience of the user regarding how he/she will feel in contact with the interface. It is desirable that an interaction system gives its users agreeable, satisfying, fun, interesting, useful, motivating, aesthetically attractive, compensating and/or emotionally adequate moments [14]. Rarely will it be possible to encompass all these characteristics simultaneously. Each project needs to highlight which, among so many aspects, is more important to its system. In the ETC case, the intention is that the environment should promote interaction and group work being agreeable and aesthetically nice and that it should stimulate creativity.

Having defined the objectives and the main usability goals and experience of users to be searched for to develop the system, we went on to a new design that tackled the deficiencies of the previous model. The next segments highlight some of the problems encountered in the previous version and how they were solved in the new version.

\section{ETC: The Construction of a New Interface Focused on Interaction Design}

Constant technological innovations in our days make software and hardware easily obsolete and cause an endless search for new systems. It is no different with systems developed for Education that need constant recycling. Such is the trend that it has been observed that the editor needed to be updated through suggestions made by users of ETC since 2002. The previous project of the editor presented navigation problems

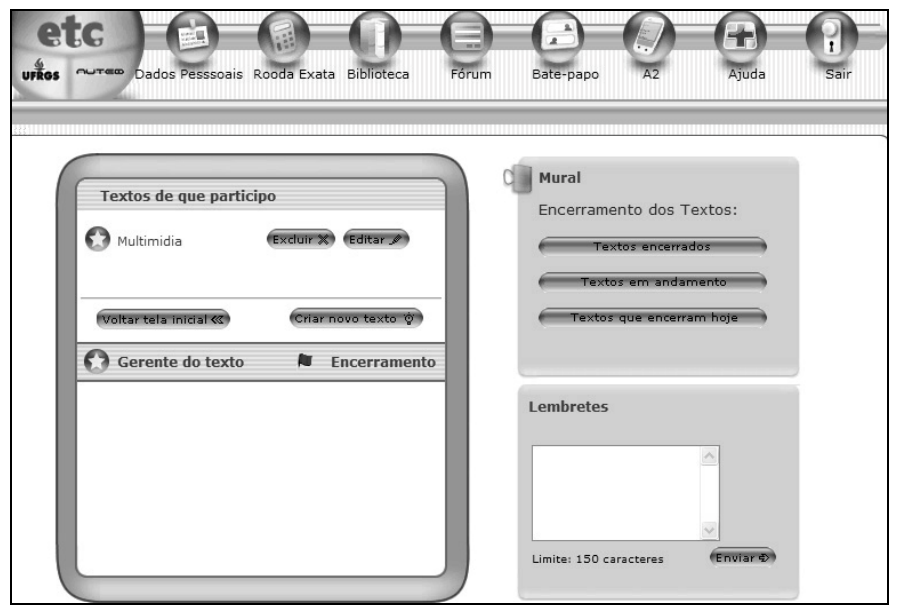

Fig. 1. Previous ETC version of text management interface 
with links that were difficult to identify because they were scattered through the pages. The visual information lacked unity and coherence, with an excess of dispensable elements and without any hierarchical definition. User performance was harmed due to time lost trying to understand how the system worked. In Fig. 1 we can see one of the content management pages from the previous version of ETC.

According to Nielsen [10] interfaces must not contain irrelevant or rarely used information because extra units of information compete with relevant information and reduce their visibility. The interaction for ETC's new version aims to cut down on noise in communication and brought a cleaner and clearer interface, as shown in Fig. 2. The new design meant to create a non-polluted environment with blank areas, driving the look of the users to the content that matters.

Lévy claims that "human memory is structured in such a way that it understands and retains better that that is organized according to spatial relations."'[8]. For the new ETC version, units of information were re-organized and hierarchized according to their relevance and function and re-distributed in a more harmonious way following a construction grid.

For Nielsen [10] the core issue as far as navigation is concerned is to inform the user where he is, identifying the site well, preferably with a logo positioned on the upper left corner. In addition, it is also necessary to show the user clearly where he/she was previously or where he/she can go, in other words, which ways he/she took in the present tool to be where he/she is at the present moment and where he/she still can go. This matter was tackled in the new ETC interface with a heading: site logo and brand and some localization links, such as home, site map and contact. In a vertical column links were placed creating a new menu, as shown in Fig. 2. These elements should remain constant throughout the pages of the site as it guarantees visual unity to the interface as well as navigation stability.

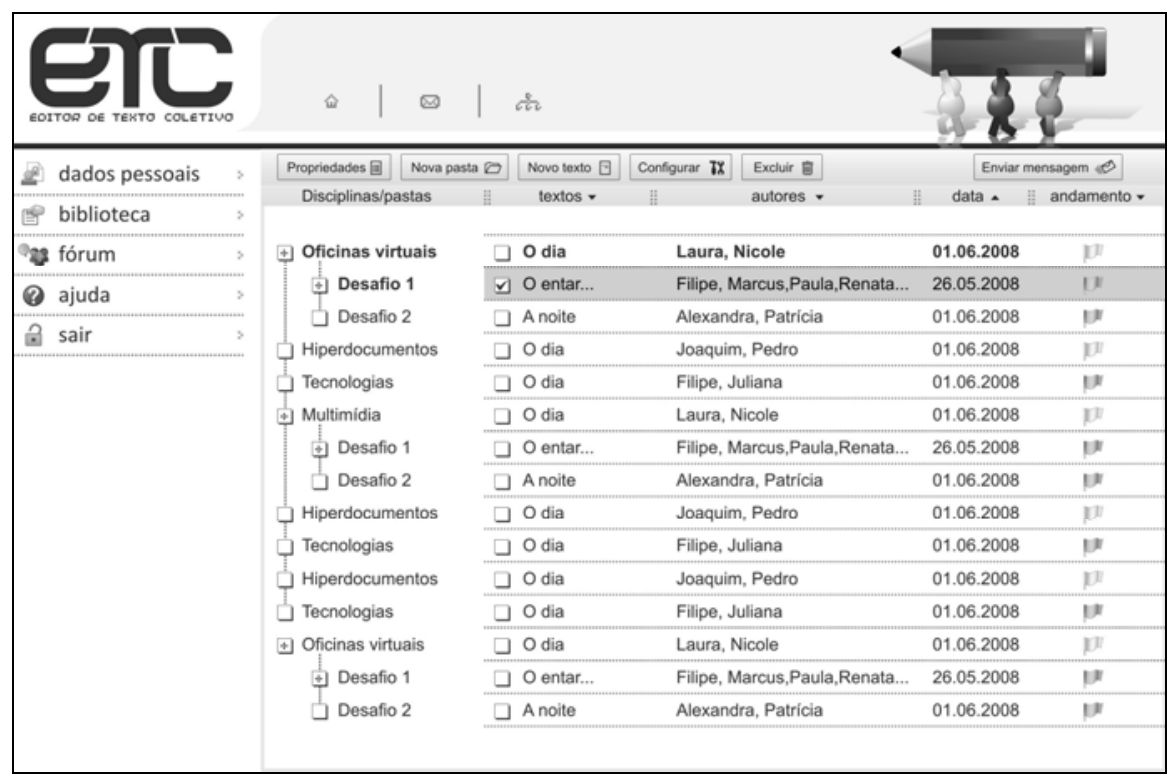

Fig. 2. New ETC interface 
Fleming [10] lists some characteristics of sites with good navigability. Among them, two that are desirable to this project: consistency and contextualization. Consistency refers to the way the system guides its user through standard menus throughout the pages and contextualization refers to how clear the visual links' definition is. For Nielsen [10], consistency refers to keeping presentation homogeneous and coherent. Consistency is a characteristic that guides and makes navigation easy to learn, one of the usability goals of the new ETC project. Thus, a new visual identity and new menus were developed aiming to guarantee consistency in all the pages of the site. Fig. 2 and 4 show all the pages of ETC and demonstrate how the pattern was maintained.

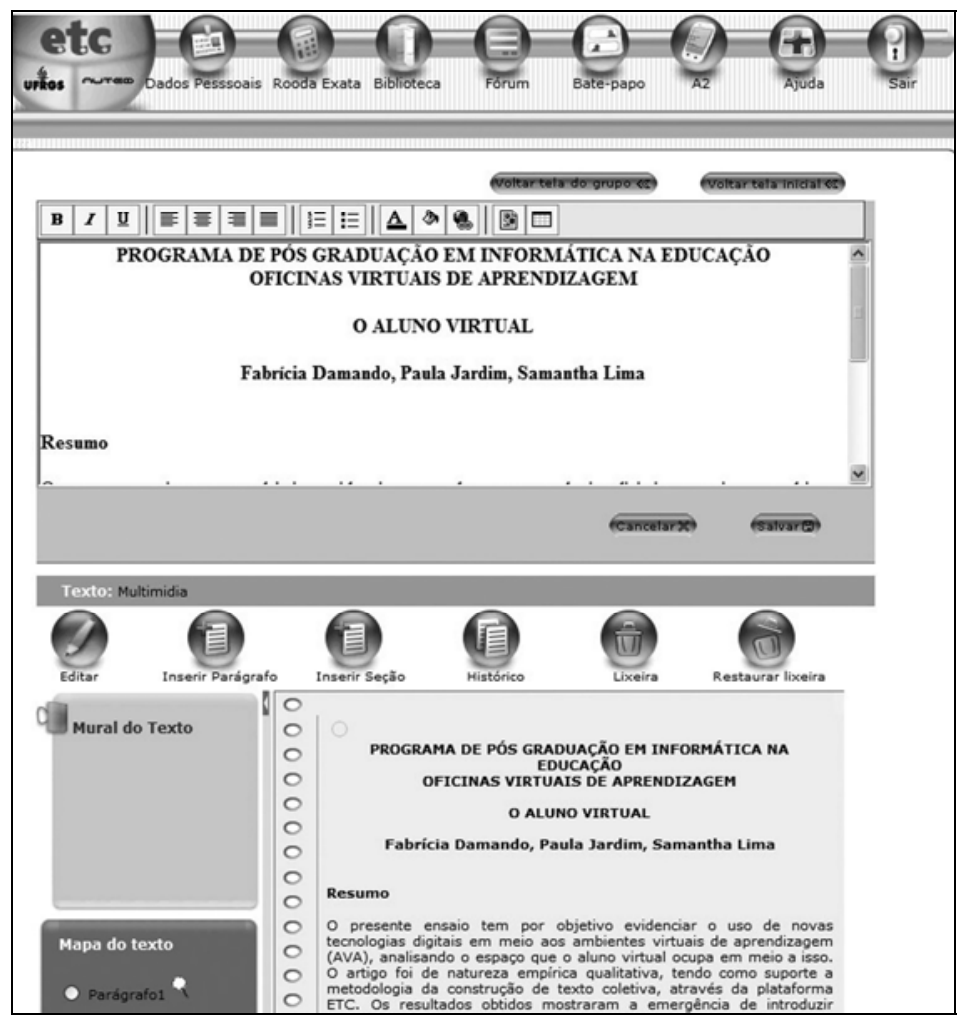

Fig. 3. Previous version Interface of text editor

In a menu, alternatives are presented enabling the user to choose an action. According to Dul and Weerdmeester [5] the advantage of the menu is that the user needs little previous experience to understand it, in other words, the system is simple to operate even for beginners. This format requires little digitations and little mental effort, something that is considered adequate to the system in project once the idea is to diminish the cognitive load. In the new interface of the ETC five menu links were worked with allowing for possible tool additions identified as necessary. The ideal is to work with a menu of up to seven alternatives so that selection can be made quickly. 
To ensure link contextualization, new icons were drawn. Such icons personalize the Editor, make function recognition instantaneous and contribute to another usability goal which is to help the user remember them in a second visit.

Fleming [9] also highlights that a site must guarantee that time will be saved allowing user to quickly arrive where he/she needs to. In this sense, Norman [11] highlights visibility, claiming that functions should be within reach of the user or else the user will have difficulties finding them and knowing how to use them. This author claims that the more visible functions are, the easier it will be for the user to proceed. Filatro [7] advises that a system should enable the navigator the use of menus to find what is necessary in no more than two or three clicks. In the new ETC, we tried to reduce the number of clicks by concentrating the management that was spread throughout 11 pages to one general page of content management. Fig. 2 presents a page that was developed concentrating all the pages of the previous version to only one.

The page meant for text editing is where all the actions of users are concentrated as it is on this page that the collective text productions take place. Fleming [9] highlights that the most important in a tool is that this tool works to help the user reach his/her objectives. It is necessary, therefore, that the interface be simplified and lead the user, clearly, to the functions that help him/her.

The previous model of page editing underwent the same problems of management pages, cited above: lack of visual unity, hierarchy and organization, as shown in Fig. 3. Some of these problems were solved with the new heading and the new lateral menu, as specified above. New icons were then developed and implemented right on the menu bar and on the bottom bar of the editor. Thus, grouped and duly identified, the functions can be easily found and understood.

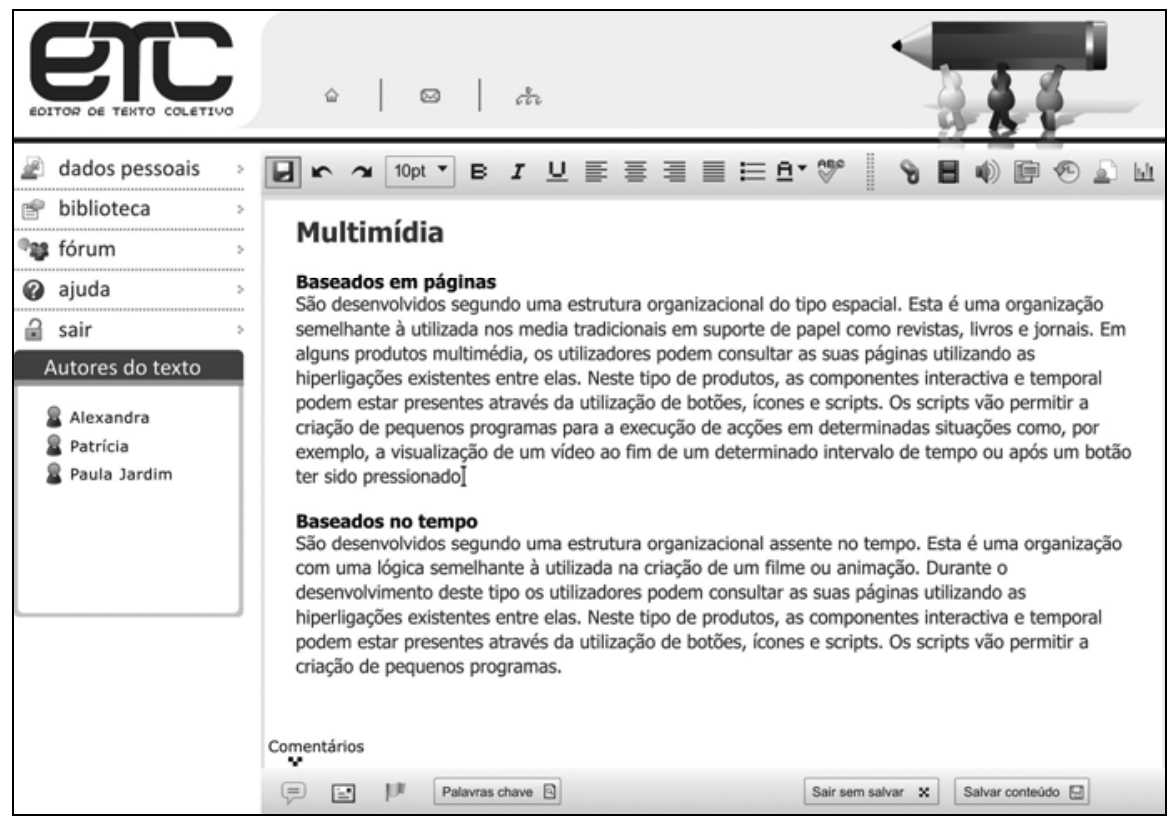

Fig. 4. New interface of ETC text edition 
Another meaningful change took place in the editing box, which now shows the whole text and not just the paragraphs. This way, it was possible to eliminate the bottom area of text exhibition and the box for choosing the paragraph to edit (Fig. 3). Based on these considerations and with the innovations presented, the new editing page has become cleaner, more spacious and cognitive overload-free, which allows more room for productivity and creativity. The environment has become, therefore, more agreeable and aesthetically pleasant living up to the goals proposed in relation to the experience of users, as we can see in Fig. 4.

Nielsen [10] states that web pages normally look alike, with relatively similar interaction techniques and layouts which is an advantage as it allows for some skills transference from one site to another. This author also states that, according to his studies of usability, users complain about sites that try to use drastically different navigation interfaces from the majority. Complementing this idea, according to Radfather [16], people look for patterns and recognizable shapes in the environments for their guidance. The new ETC page edition was drawn, on purpose, similarly to other existing tools for textual production (like Word, Microsoft and Google Docs, for example), so some familiarity can be found, making the work of the user easier.

\section{Final Considerations}

The world offers new alternatives regarding communication and information technology every day. Education must follow these trends regarding the offer of resources which allow knowledge construction to happen naturally and spontaneously, even if mediated by the screen of a computer.

Through the new ETC interface design we look for greater efficacy in the system in order to meet expectations, and, still we intend it to be more efficient as far as helping the user to perform his/her tasks. Moreover, the changes presented in this article also aim to allow it to be part of Web 2.0. According to Filatro [7] interface and navigation logic in Web 2.0 tend to be simpler due to international patterns and protocols. Thus, code-free tools can be easily incorporated one to another after being tested by many users. This way, we hope the Editor can become more user-friendly and accessible to a larger number of people and that it can help them in their productivity.

For Nielsen [10] one of the main objectives of a web page design is to establish credibility. Due to the enormous amount of information available on the Internet and due to the impossibility of identifying sources, the choice of reliable content is difficult for any person. Since the first contact of a user with the system is always visual, it is very important that a site have good appearance so as to be seen as worthy of credit.

In this sense, having in mind the popularization of the Editor, its logo brand was re-formulated and re-positioned, making it ready to become an Internet free tool. We aim, therefore, to create an identity with the other web collaborative tools, adding common visual elements of all but, at the same time, giving it personality and credibility, contributing to consolidate its image as a useful tool for intellectual productivity and collective interaction. 
Validation of the new interface is predicted to the first semester of 2009, when it will applied in extension, graduate and post-graduate courses. We hope that, through collective writing activities proposed, it be possible to identify efficacy as well as possible limitations/advantages of the new interface developed for the Collective Text Editor. From the experience, analysis of the new material will be possible, both from pedagogical and interaction design perspectives, aiming possible adjustments and/or improvements as well as the availability of use to the community, outside the university.

\section{References}

1. Axt, M., et al.: Once upon a time.. co-authorship in collective narratives intersectioned by digital technologies. In: XII Brazilian Simposium of Education Technologies, Vitoria/ES (2001)

2. Behar, P.A., et al.: Construction and Application of ETC - collective text editor. In: Barbosa, R.M. (org.) Virtual Learning Environments, Porto Alegre, only edition, pp. 1728 (2005)

3. Behar, A.B., Macedo, A.L., Mazzocato, S.B., Bitencourt, J.B.: Collective Writing: the potential of a Groupware via Web. In: RENOTE: Magazine of New Educational Technologies, Porto Alegre, UFRGS (July 2006)

4. Behar, P.A., Macedo, A.L., Mazzocato, S.B.: Support Technologies to Collective Work: planning and application of a learning object. In: XVIII Brazilian Simposium of Education Technologies, São Paulo. XVIII Brazilian Simposium of Education Technologies, pp. 90 99. SBC - Brazilian Computer Society, Porto Alegre (2007)

5. Dul, J., Weerdmeester, B.: Practical Ergonomy, 2nd edn. Edgard Blucher Ltda, São Paulo (1995)

6. Fetter, L.C.: Typos, typography: design of and com. In: Bozzetti, N., Bastos, R. (org.) Thinking design 2. Ed. Uniritter, Porto Alegre (1995/ 2008)

7. Filatro, A.: Instructional Design in practice. Pearson Education of Brasil, São Paulo (2008)

8. Lévy, P.: Intelligence Technologies: the future of thinking in the computer era. Editora 34, São Paulo (1993)

9. Memoria, F.: Internet Design: projecting the perfect experience. Elsevier, Rio de Janeiro (2005)

10. Nielsen, J.: Projecting websites. Campus, Rio de Janeiro (2000)

11. Norman, D.A.: The design of everyday things. Basic Book, New York (2002)

12. Piaget, J.: Sociological Studies. Forense, Rio de Janeiro (1973)

13. Piaget, J.: Reflex Abstraction: Logical-mathematical relationships and order in spacial relations. Artes Médicas, Porto Alegre (1995)

14. Preece, J.: Interaction design: beyond human-computer interaction, vol. xi. John Wiley \& Sons, New York (2002)

15. Passos, J.E.: Interaction Design for Collective Text Editor - ETC. Monography (course conclusion ) University Center Ritter dos Reis. Porto Alegre (2008)

16. Radfahrer, L.: Design / Web / Design. Market Press, São Paulo (2001)

17. Sawaya, M.R.: Computer language and internet dictionary: English-Portuguese. Nobel, São Paulo (1999)

18. Tammaro, S.G., Mosier, J.N., Goodwin, N.C., Mosier, J.N.: Collaborative Writing Is Hard to Support: A Field Study of Collaborative Writing. Computer Supported Cooperative Work: The Journal of Collaborative Computing 6, 19-51 (1997) 